\title{
Evaluation of tools to assess psychological distress: how to measure psychological stress reactions in citizen responders- a systematic review
}

Astrid Rolin Kragh ${ }^{1 *}$, Fredrik Folke ${ }^{1,2}$, Linn Andelius ${ }^{1}$, Emma Slebsager Ries ${ }^{1}$, Rasmus Vedby Rasmussen ${ }^{2}$ and Carolina Malta Hansen ${ }^{1,2}$

\begin{abstract}
Background: Dispatched citizen responders are increasingly involved in out-of-hospital cardiac arrest (OHCA) resuscitation which can lead to severe stress. It is unknown which psychological assessment tools are most appropriate to evaluate psychological distress in this population.

The aim of this systematic review was to identify and evaluate existing assessment tools used to measure psychological distress with emphasis on citizen responders who attempted resuscitation.

Methods: A systematic literature search conducted by two reviewers was carried out in March 2018 and revised in July 2018. Four databases were searched: PubMed, Psyclnfo, Scopus, and The Social Sciences Citation Index. A total of 504 studies examining assessment tools to measure psychological distress reactions after acute traumatic events were identified, and 9 fulfilled the inclusion criteria for further analysis. The selected studies were assessed for methodological quality using the Scottish Intercollegiate Guidelines Network.

Results: The Impact of Event Scale (IES) and The Impact of Event Scale-Revised (IES-R) were the preferred assessment tools, and were used on diverse populations exposed to various traumatic events. One study included lay rescuers performing bystander cardiopulmonary resuscitation and this study used the IES. The IES and the IES-R also have proven a high validity in various other populations. The Clinical administered PTSD scale (CAPS) was applied in two studies. Though the CAPS is comparable to both the IES-R and the IES, the CAPS assess PTSD symptoms in general and not in relation to a specific experienced event, which makes the scale less suitable when measuring stress due to a specific resuscitation attempt.

Conclusions: The IES and the IES-R seem to be solid measures for psychological distress among people experiencing an acute psychological traumatic event. However, only one study has assessed psychological distress among citizen responders in OHCA for which the IES-R scale was used, and therefore, further research on this topic is warranted.
\end{abstract}

Keywords: Citizen responders, Out-of-hospital cardiac arrest, Psychological impact, Stress disorder assessment

\footnotetext{
* Correspondence: astridmarierolin@gmail.com

${ }^{1}$ Emergency Medical Services Copenhagen, University of Copenhagen,

Telegrafvej 5, DK-2750 Ballerup, Copenhagen, Denmark

Full list of author information is available at the end of the article
}

(c) The Author(s). 2019 Open Access This article is distributed under the terms of the Creative Commons Attribution 4.0 International License (http://creativecommons.org/licenses/by/4.0/), which permits unrestricted use, distribution, and reproduction in any medium, provided you give appropriate credit to the original author(s) and the source, provide a link to the Creative Commons license, and indicate if changes were made. The Creative Commons Public Domain Dedication waiver (http://creativecommons.org/publicdomain/zero/1.0/) applies to the data made available in this article, unless otherwise stated. 


\section{Background}

Bystander cardiopulmonary resuscitation (CPR) is crucial to improve chances of survival following out-ofhospital cardiac arrest (OHCA) and is a cornerstone in both the European and American resuscitation guidelines, [1, 2]. Each year more than 350,000 OHCAs in the United States and 300,000 OHCAs in Europe are registered, $[3,4]$. Several initiatives have been implemented in the past decades to increase bystander CPR, such as widespread campaigns to raise awareness among the general population, mandatory CPR training in schools, and other educational institutions, [5-7].

Consequently, the number of persons attempting CPR has increased in several countries, and in the U.S., rates of bystander CPR increased from $28 \%$ in 2005 to more than $46 \%$ in 2016, [8]. In Denmark the proportion of patients receiving bystander CPR rose from $21 \%$ in 2001 to $45 \%$ in 2010, [5].

The Cardiac Arrest Registry to Enhance Survival from the U.S. reported 30,063 cases had received bystander CPR in 2017. The number of bystanders involved in cardiac arrests is probably higher, since in many cases, several bystanders attempt resuscitation together. This number is likely to grow as authorities as well as international guidelines on resuscitation increasingly encourage citizens to attempt CPR and a growing number of countries have initiated citizen first responder programmes based on a smartphone application for dispatch of citizen responders to OHCAs, [1, 2, 9-11].

A number of qualitative interview studies have shown that citizen responders experience stress-related symptoms after participating in resuscitation attempts, [12-15]. However, the persistence and degree of the stress reactions among citizens who perform bystander CPR remains unknown. Understanding how to measure stress among bystanders who performed resuscitation is of utmost importance as this is not only a growing population, but also one acting by recommendation of health authorities.

The objective of this systematic review was to identify and evaluate existing assessment tools used to measure stress among people experiencing a traumatic event and evaluate whether these assessment tools are suitable for measuring psychological distress among citizen responders who have performed bystander CPR. The study aimed to identify one scale that relates to a specific traumatic event, is able to predict the risk of persistent psychological distress at 4 weeks after the event and has been validated among different population groups.

\section{Methods}

This systematic review was reported using PRISMA guidelines (Preferred Reporting Items for Systematic Reviews and Meta-Analyses). The guidelines are preferred for reporting items for systematic reviews and metaanalyses and developed by Cochrane Collaboration, [16].

\section{Information sources and search}

A literature review with a systematic search approved by a professional research librarian was conducted by two reviewers $(A K, R R)$ via the University of Copenhagen between 17th and 20th of March 2018. The search was revised on 23th of July 2018. Studies were identified through searches in four databases using keywords combined from the PICO model (Table 1): PubMed, PsycINFO, Scopus, and The Social Sciences Citation Index. Covidence software program was applied to identify duplicates, screen-imported studies, and support the study selection process. This study was conducted without a review protocol.

\section{Eligibility criteria}

The research question was developed following the PICOS (population, intervention, comparison, outcome and study design) format, [17]. Studies were considered eligible for inclusion if they met all of the following criteria: 1) Included citizen responders participating in a resuscitation attempt, or other persons involved in an acute psychologically traumatic experience (=population), 2) Applied or examined validated inventory tools to assess psychological distress or psychological impact after an experienced traumatic event (=intervention), 3) Measured stress disorders, psychological impact, or post-traumatic stress disorder (PTSD) related symptoms (=outcome). Excluded were studies with either of the following criteria: Performed on a population not experiencing an acute traumatic event, included persons under the age of 18 years or persons with a psychiatric diagnosis, and studies applying an inventory tool which was not validated. Conference abstracts and expert narratives were excluded due to the inability to evaluate the risk of bias. No language or time limitations were applied. Since many of

Table 1 Search terms used in PICO model

\begin{tabular}{lll}
\hline Participant & Intervention/Phenomenon of Interest & Context or Outcome \\
\hline Lay rescuer OR rescuer* & Psychological assessment tool & Psychological impact \\
Bystander rescuer OR bystander* & Measure of distress & Stress disorder \\
Persons who perceived traumatic event & Impact of event scale & Post-traumatic stress symptoms \\
Persons who experiences traumatic event & Stress response syndromes
\end{tabular}

*Is a truncation symbol 
the assessment tools for identifying stress disorders are based on questionnaires and interviews, both quantitative and qualitative studies were considered for inclusion.

\section{Study selection}

Two reviewers (AR, RR) independently conducted the literature search based on the title and abstract and undertook the full-text review. In case of disagreement, the paper was re-read and discussed between the reviewers until consensus was reached. Studies that assessed psychological impact or stress disorders with a validated tool among people experiencing a specific acute traumatic event were selected.

Due to the lack of studies examining inventory tools to measure psychological stress reactions among citizen responders attempting resuscitation, there was considerable variability in the population group and therefore also in the cause of stress disorders in the included studies. Thus, as presented in Table 2, the selected studies included a wide range of participants (health care professionals, trauma patients, persons experiencing parental bereavement, citizen responders, etc.). The traumatic events varied from accidents to work-related trauma and injuries.

\section{Quality assessment}

The risk of bias was assessed using The Scottish Intercollegiate Guidelines Network (SIGN) in each study, [18]. Sample strategy, method, and psychological assessment tool were evaluated, and each study was rated with ,-+ or ++ . Specifications are presented in Table 3.

\section{Results}

The literature selection process and electronic search strategy is presented in the flow diagram Fig. 1 and resulted in the following: PubMed $(n=414)$, PsycINFO $(n=61)$, Scopus $(n=27)$, SSCI $(n=2)$. There were 50 duplicates identified, which resulted in 454 exclusive titles reviewed by AR and RR.

A total number of 441 studies were excluded as they did not meet the inclusion criteria described previously.

Of 13 papers that appeared relevant for inclusion, four were excluded following full-text reading resulting in a total number of nine studies included in a qualitative synthesis.

Four inventory tools were identified through the nine included studies: The Impact of Event Scale (IES), the Impact of Event Scale-Revised (IES-R), the Clinical Administered PTSD Scale (CAPS), and the Post-Traumatic

Table 2 Characteristics of all papers included in the review

\begin{tabular}{|c|c|c|c|c|c|}
\hline Publication & Aim & Participants & Event & Assessment tool & Outcome \\
\hline $\begin{array}{l}\text { Zilberg } \\
\text { et al., } 1982\end{array}$ & $\begin{array}{l}\text { A validation of Impact of Event } \\
\text { Scale }\end{array}$ & $\begin{array}{l}\text { Patients who lost a } \\
\text { parent }\end{array}$ & Experiences parental bereavement & IES & $\begin{array}{l}\text { Stress } \\
\text { response } \\
\text { syndromes }\end{array}$ \\
\hline $\begin{array}{l}\text { Mooren } \\
\text { et al., } 2004\end{array}$ & $\begin{array}{l}\text { To assess the psychometric value of } \\
\text { the Dutch version of the IES }\end{array}$ & Multiple & $\begin{array}{l}\text { Work-related trauma, war-related } \\
\text { trauma, disasters }\end{array}$ & IES & $\begin{array}{l}\text { Post- } \\
\text { traumatic } \\
\text { stress } \\
\text { responses }\end{array}$ \\
\hline $\begin{array}{l}\text { Beck et al., } \\
2008\end{array}$ & $\begin{array}{l}\text { Factor structure, psychometric } \\
\text { features and ability of IES- R to } \\
\text { differentiate individuals w/wo PTSD }\end{array}$ & $\begin{array}{l}\text { Motor vehicle } \\
\text { accident suvivors }\end{array}$ & $\begin{array}{l}\text { Motor vehicle accident involving actual } \\
\text { or threatened death or serious injury }\end{array}$ & IES-R and CAPS & PTSD \\
\hline $\begin{array}{l}\text { Eid et al., } \\
2009\end{array}$ & $\begin{array}{l}\text { Reliability and validity of the } \\
\text { Norwegian version of IES-R }\end{array}$ & $\begin{array}{l}\text { Psychology students } \\
\text { (non-clinical sample) }\end{array}$ & $\begin{array}{l}\text { Indirectly exposed through media } \\
\text { reports from a tsunami disaster }\end{array}$ & IES-R & $\begin{array}{l}\text { Post- } \\
\text { traumatic } \\
\text { stress } \\
\text { symptoms }\end{array}$ \\
\hline $\begin{array}{l}\text { Sveen } \\
\text { et al., } 2010\end{array}$ & $\begin{array}{l}\text { Assess the Swedish version of IES } \\
\text { and IES-R. }\end{array}$ & Patients with burns & Burn injury & IES-R and IES & PTSD \\
\hline $\begin{array}{l}\text { Bryant } \\
\text { et al., } 2011\end{array}$ & $\begin{array}{l}\text { To assess the capacity of acute } \\
\text { stress disorder to predict } \\
\text { posttraumatic psychiatric disorders }\end{array}$ & $\begin{array}{l}\text { Trauma patients } \\
\text { admitted to hospital } \\
\text { after traumatic injury }\end{array}$ & Traumatic injury such as traumatic fall & $\begin{array}{l}\text { Clinical } \\
\text { Administered } \\
\text { PTSD Scale } \\
\text { (CAPS) }\end{array}$ & $\begin{array}{l}\text { Acute stress } \\
\text { disorder }\end{array}$ \\
\hline $\begin{array}{l}\text { Schütte } \\
\text { et al., } 2012\end{array}$ & $\begin{array}{l}\text { To examine the predictive variables } \\
\text { of PTSD }\end{array}$ & Police Officers & $\begin{array}{l}\text { Experienced traumatic incidence on } \\
\text { duty }\end{array}$ & $\begin{array}{l}\text { Structured Clinical } \\
\text { Interview for } \\
\text { DSM-IV and IES-R }\end{array}$ & $\begin{array}{l}\text { PTSD and } \\
\text { Acute Stress } \\
\text { Disorder }\end{array}$ \\
\hline $\begin{array}{l}\text { Waller } \\
\text { et al., } 2015\end{array}$ & $\begin{array}{l}\text { Association between number of } \\
\text { stressful events and severity of } \\
\text { PTSD symptoms. }\end{array}$ & $\begin{array}{l}\text { Australian Defence } \\
\text { Force }\end{array}$ & $\begin{array}{l}\text { Stressful events or traumatic } \\
\text { experiences on deployment, workplace } \\
\text { stressors and relationship/family issues }\end{array}$ & $P C L-C$ & PTSD \\
\hline $\begin{array}{l}\text { Zijlstra } \\
\text { et al., } 2015\end{array}$ & $\begin{array}{l}\text { PTSD-related symptoms among lay } \\
\text { rescuers performing CPR }\end{array}$ & $\begin{array}{l}\text { First arriving lay } \\
\text { rescuers performing } \\
\text { bystander CPR }\end{array}$ & $\begin{array}{l}\text { Participation in resuscitation attempt } \\
\text { either by providing CPR or using AED }\end{array}$ & IES & $\begin{array}{l}\text { Post- } \\
\text { traumatic } \\
\text { stress related } \\
\text { symptoms }\end{array}$ \\
\hline
\end{tabular}


Table 3 Specifications of quality assessments

\begin{tabular}{lll}
\hline Publication & Quality (SIGN) & SIGN comments \\
\hline Zilberg et al., 1982 & - & Poorly described method \\
Mooren et al., 2004 & ++ & Well described method and statistical analysis \\
Beck et al., 2008 & ++ & Well described sample selection, randomization and method \\
Eid et al., 2009 & + & Well described sample, poorly described method \\
Sveen et al., 2010 & + & Inadequate described method \\
Bryant et al., 2011 & + & Well described method \\
Schütte et al., 2012 & + & Prospective study design \\
Waller et al., 2015 & + & Retrospective design, but well described method \\
Zijlstra et al., 2015 & ++ & Prospective study design \\
\hline
\end{tabular}

Stress Disorder Checklist (PCL), which are briefly described in the following. All these tools have been validated on a wide range of populations such as police officers, burn patients and motor vehicle accident survivors, [19-21].

\section{The impact of event scale and the impact of event scale-} revised

The Impact of Event Scale (IES) and Impact of Event Scale-Revised (IES-R) were most frequently used on different populations exposed to various acute traumatic events $(n=7)$. Both the IES and the IES-R have previously been validated and proven useful to predict PTSD, $[19,22,23]$.

The original IES is a 15-item self-reported scale that assesses subjective distress caused by traumatic events, such as a resuscitation attempt. The scale is designed to assess the frequency of intrusive and avoidant stress symptoms with respect to a certain identified trauma, not related with traumatic symptoms in general. Intrusive symptoms refer to flashbacks to the event or dissociative reactions where it seems as if the trauma is

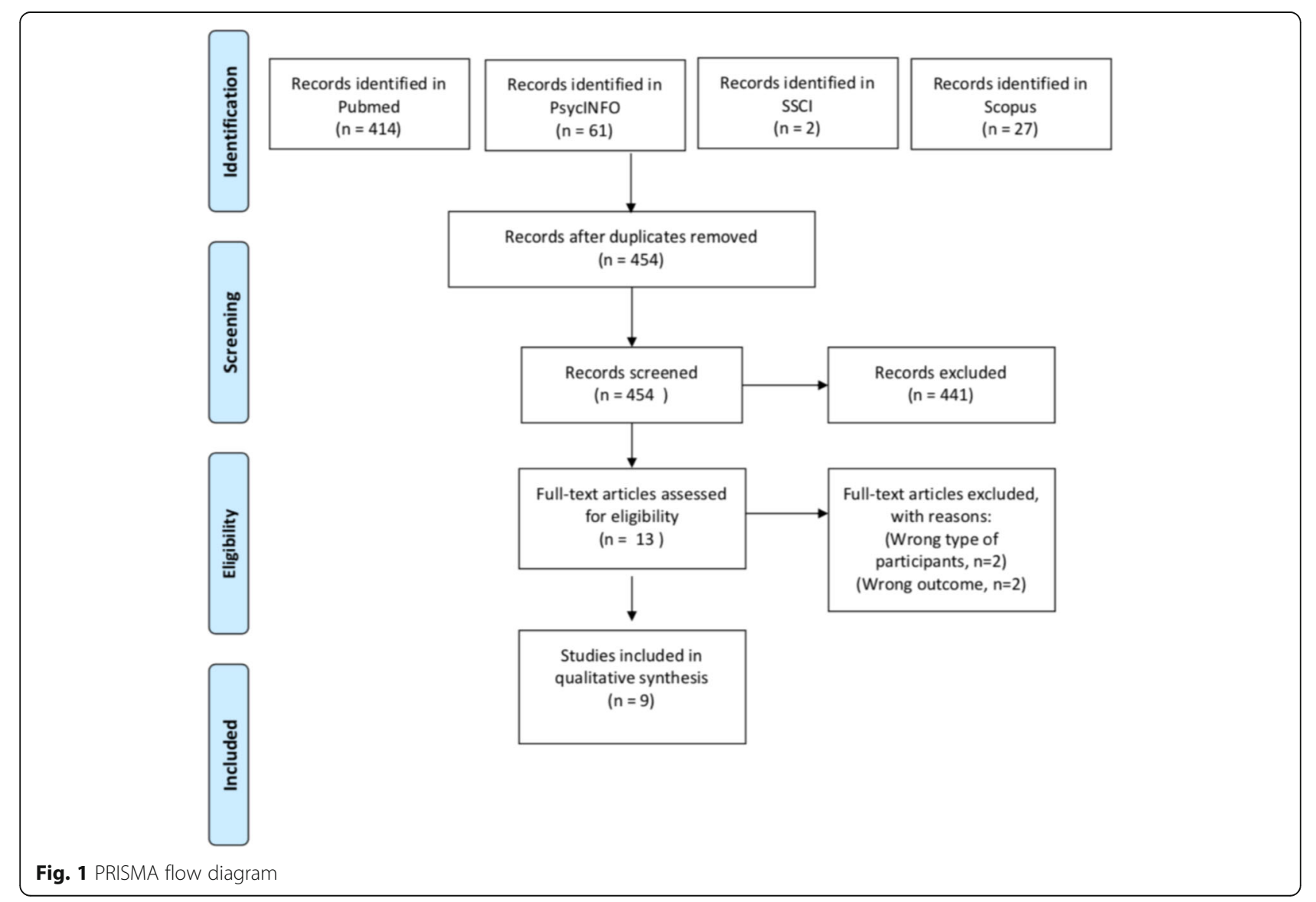


reoccurring. Avoidant stress symptoms are expressed in questions that concern avoiding getting upset and trying not to think of the event.

The scale has been revised to the IES-R which contains seven additional items related to the hyperarousal symptoms of PTSD, such as anxiety and insomnia. These items were added to match the diagnose criteria for PTSD in the Structured Clinical Interview for Diagnostic and Statistical Manual of Mental Disorders (DSM). It has been shown that high IES scores 1 week after a traumatic event predicts PTSD 6 months later with $92 \%$ sensitivity $[24,25]$.

The maximum overall score possible in the IES-R is 12. The sum of the means of each subscale is recommended instead of raw sums. High levels of internal consistency and discriminative validity have been previously reported for the IES-R. A Japanese translation of the scale reported test-retest values and Rash et al. described a high level of internal consistency among total and subscale scores (Crohnbach's alpha 0.95). The convergent validity has been reported with consistent and high correlations between the IES- $\mathrm{R}$ and related measures of PTSD [20, 26-28].

A prospective observational study conducted by Zijlstra et al., evaluated the perceived short-term impact on psychological wellbeing of lay rescuers performing bystander CPR, [29]. Furthermore, they aimed to investigate the level of PTSD-related symptoms among bystanders $4-6$ weeks after resuscitation attempts. This study was the only publication from the literature search measuring stress reactions with a validated inventory tool among citizen responders attempting resuscitation. The authors applied the IES to measure psychological symptoms of PTSD among the participants $(n=189)$, by sending the scale to citizen responders 4 weeks after the resuscitation attempt. The authors found that $41 \%$ of the responders reported no/mild short-term psychological impact, $46 \%$ bearable impact and $24 \%$ severe impact on the IES. However, no of the citizen responders scored > 26 (moderate or severe stress), 19\% scored 9-25 (mild stress), and $81 \%$ scored $0-8$ (no stress). None of the citizen responders reporting severe or bearable psychological impact on the short term scored more than mild stress levels on the IES (4-6 weeks after the event).

The IES has furthermore been validated to assess the psychological impact of a variety of traumas in a study by Van der Ploeg et al., [23]. In this study, the authors evaluated the psychometric value of the Dutch version of the IES in three different samples of individuals who had experienced various traumatic stressors (work-related trauma, war-related trauma, and disasters). The authors found that the IES is a justified and valid instrument with a robust factor structure. An earlier study by Zilberg et al. reported a detailed description of the IES and encouraged cross-validational data and analyses, [30]. The study concluded that the IES is a sensitive measure of change, suitable for intervention studies utilizing repeated measurements over time.

The IES-R has correspondingly to the IES been validated on a variety of different populations experiencing acute psychologically traumatic events. In a publication by Sveen et al., the authors studied the Swedish version of the IES-R and validated it against the DSM in a population of burn victims, [19]. The authors examined the ability of the scale to discriminate between individuals with and without PTSD. They found that participants with a positive PTSD diagnosis had higher scores on IES- $\mathrm{R}$ than those without a diagnosis. The results showed that the IES-R has good properties as a screening tool for the diagnosis of PTSD in patients with burns 1 year after injury. The IES-R has also proven useful in a study by Beck et al. based on a sample of motor vehicle accident survivors $(n=182)$ who sought treatment for mental health problems following the injury, [20]. The authors examined the factor structure of the IES-R and its related psychometric features as well as the ability of the scale to differentiate between individuals with and without diagnosable PTSD. Based on their results, the authors suggested that the IES-R is not simply a measure of general distress but appears to have specific agreement in the assessment of PTSD symptomatology. The authors concluded that the scale had possibility to differentiate between individuals with and without PTSD although it was not developed as a diagnostic tool. The study suggests that the IES-R seems to be a solid measure of post-trauma phenomena that can enlarge related assessment approaches.

Another prospective study by Schütte et al. provides evidence that the IES-R is a suitable scale in predicting the development of stress symptoms and PTSD after experiencing an acute psychologically traumatic event, [21]. The authors investigated the predictors for the development of PTSD in 59 police officers who had experienced a traumatic incident during duty where the participants completed the IES-R immediately after the event and 6 months later.

The reliability and validity of the IES-R has moreover been examined in a Norwegian study by Eid et al., [31]. The study was based on a non-clinical sample consisting of 311 undergraduate psychology students who were asked to review media reports from a tsunami disaster and were subsequently asked to rate their traumatic symptoms. The authors found that the Norwegian version of the IES-R has satisfactory psychometric properties with good reliability an accuracy in terms of detecting dimensions of PTSD-symptoms. The authors recommended to use the scale to measure traumatic symptoms with respect to a certain trauma in future 
studies. However, none of the students had been personally exposed to the tsunami but were only exposed through the media. The IES-R was administered to the students about 3 weeks after the disaster.

\section{The CAPS - clinical administered PTSD scale}

The Clinical administered PTSD scale (CAPS) is known as the golden standard in PTSD assessment and has been revised several times. The scale is a 30 -item structured clinical interview that in addition to the 17 PTSD symptoms includes items pertaining to the dissociative symptoms required for a diagnosis of Acute Stress Disorder. The newest version of the scale (CAPS-5) is a structured interview that assesses PTSD symptoms over the past week and makes current as well as lifetime diagnosis of PTSD, [32].

A longitudinal study by Bryant et al. was performed among survivors of traumatic injury, [33]. The study reported analyses that evaluated the capacity of Acute Stress Disorder in the initial month after trauma to predict a range of disorders including PTSD 12 months later. Acute Stress Disorder was assessed using the CAPS in the initial month after trauma. The authors found that $10 \%$ of the participants met criteria for Acute Stress Disorder at the initial assessment. After 12 months, $31 \%$ had a psychiatric disorder of which $10 \%$ met the criteria for PTSD. The study concluded that the majority of the trauma survivors who developed PTSD did not meet Acute Stress Disorder criteria in the initial month. Only a third of patients who did meet Acute Stress Disorder criteria developed PTSD. The acute stress disorder criteria measured by the CAPS has limited utility in identifying trauma-exposed individuals who are at risk for PTSD.

\section{The PCL - post-traumatic stress disorder checklist}

The PCL is a psychometrically validated checklist developed to measure the 20 DSM-5 symptoms of PTSD. The scale is a self-reported measure and has various purposes, such as PTSD-screening, PTSD-diagnosing, and symptom change monitoring during and after treatment, $[34,35]$. A retrospective cohort study conducted by Waller et al. investigated the association between numbers of stressful events and the severity of PTSD symptoms using the PCL. The authors aimed to explore if new stressful events trigger memories of previous events. A cohort consisting of 1119 Australian military personnel deployed to the Middle East, was asked to report traumatic exposures associated with deployment. Scores on the PCL and stressful events were measured. The study found that personnel reporting more events had a higher mean PLC-score compared to those who reported no events. The study concluded that number of stressful events was significantly associated with more symptoms of PTSD, [36].

\section{Discussion}

This systematic review presents an overview over existing assessment tools used to measure psychological distress with emphasis on stress reactions among citizen responders who attempted resuscitation. We found that both the IES and the IES-R are solid measures for psychological distress among people experiencing an acute psychological traumatic event, but only one study has assessed psychological distress among citizen responders after participation in resuscitation attempts using the IES score. Therefore, future studies examining psychological distress among citizen responders in out-ofhospital cardiac arrest are warranted.

The majority of the studies included in this review (seven out of nine) examined the IES or IES-R and only one study, [29] applied a validated tool (the IES) to measure psychological stress in citizen responders who attempted resuscitation in OHCA. In accordance with the study provided by Van der Ploeg et al., [23] who suggested a predictive validity of PTSD-symptoms at minimum 4 weeks after event, Zijlstra et al. sent the questionnaire by e-mail 1 month after the resuscitation attempt, which suggests results are valid and reliable.

Despite this, a couple of limitations are worth mentioning. Several of the participants (42\%) in the study by Zijlstra et al. were off-duty professional rescuers who might cope better with stress than lay rescuers. According to a study using the IES examining people who experienced an avalanche disaster, volunteers meet PTSD criteria significantly more often than professional rescuers, [37]. Another limitation is that an interview was conducted with all bystanders included in the study before they answered the questionnaire. A recent qualitative study found that debriefing bystanders stimulates the ability to cope with emotional reactions, [38]. Consequently, the interview may have served as debriefing and thus influenced the stress score and biased the results. Moreover, the study did not include measurement of hyperarousal symptoms since the authors applied the original version of the IES and not the revised version. The study did not investigate the persistence of the perceived stress among the citizen responders as no longterm follow-up was performed.

Overall, the study contributes with important knowledge of clinical relevance to measure psychological distress among citizen responders participating in resuscitation attempts.

We found both the IES and the IES-R useful to predict PTSD-related symptoms in persons experiencing an acute traumatic event comparable to a resuscitation attempt. Since both scales have been validated on various 
groups comparable to persons attempting resuscitation, the scales might serve useful on citizen responders as well.

One study applied the CAPS to measure psychological distress among survivors of traumatic injury, [33]. A review investigating the present literature within CAPS established that the scale in general matches the results for self-report PTSD measures - particularly the IES, [39]. However, CAPS is a structured interview specifically designed for detecting PTSD. The scale assesses PTSD symptoms in general, and not in relation to a specific experienced traumatic acute event. This makes the scale unsuitable for use on citizen responders participating in resuscitation attempts. Another important issue is the inability to predict PTSD based on the presence of stress symptoms at the initial month after event since the majority of the trauma survivors who developed PTSD did not meet the Acute Stress Disorder criteria in the initial month. Since our review seeks to identify a scale with the ability to distinguish citizen responders in risk of developing stress disorders at 4 weeks post event, the CAPS does not seem to be useful as a measure. The Acute Stress Disorder Scale did not seem appropriate as a screening instrument to predict PTSD since this scale is not suitable to measure persistent psychological distress and has only been validated in few studies.

Some studies indicate that experiencing multiple similar traumatic events increases the risk of a high score on the IES-R. The study conducted by Waller et al. proved a significant association between numbers of experienced traumatic events and severity of PTSD symptoms, [36]. The findings are consistent with the cumulative effects of stressful events being associated with increasing PTSD symptoms, [40]. Hence, it might be necessary to consider the presence of earlier traumatic events among citizen responders performing CPR, to predict the persons in risk of developing PTSD related symptoms. This information may be valuable if citizen responders are exposed to more than one resuscitation attempt and may be of particular importance in programs with dispatch registered citizen responders since these have a higher chance of providing CPR in multiple cardiac arrests compared to the general population. Additionally, the studies included in this review suggest the IES/IES-R may be used in repeated assessments to predict the long-term consequences of a traumatic event such as resuscitation attempts. Zilberg et al. reported that the IES is suitable for intervention studies utilizing repeated measurements over time, [30]. This is in accordance with the study by Van der Ploeg et al. who applied the scale 1 month after the event, and found the scale to be a valid instrument with a robust factor structure, [23]. However, the study did not provide a lack of a comparison group with a clinical interview, which is typically done as part of scale validation. To achieve reliability and to determine the development of stress over time, it may be necessary to measure stress a short time after injury (30 days) and repeat measurement after 1 year. The study provided by Eid et al. found a significantly higher severity of PTSD-related symptoms among women than men, [31]. A review of the epidemiologic literature on stress disorders found the prevalence of PTSD estimated to be $5 \%$ among men and $10 \%$ among women, [41]. The presence of higher severity of PTSD-related symptoms among women than men is needed to have in mind when measuring psychological distress among citizen responders.

\section{Limitations}

This systematic literature review has several limitations. Only one study applying a validated psychological assessment tool to measure stress among citizen responders to OHCA was identified and thus, limited knowledge is available to address the aim of the study. As for any systematic literature review, there is a risk of publication bias since the searches were limited to published articles. The lack of studies using validated inventory tools to measure stress among citizen responders who performed CPR made it necessary to expand the search to participants experiencing a more undefined acute traumatic event and attempting $\mathrm{CPR}$ at cardiac arrest might elicit different psychological reactions compared to those who were physically injured. Although all included studies are observational, both SIGN and PRISMA guidelines were used. Further studies are needed regarding a broader sample of bystanders who attempted CPR.

\section{Conclusion}

Both the IES-R and the IES seem to be solid measures for psychological distress among people experiencing an acute traumatic event, although there is a lack of evidence within the field of citizen responder resuscitation. Further studies validating the scales as inventory tools for measuring psychological distress among citizen responders are recommended.

\section{Abbreviations \\ CAPS: The Clinical administered PTSD scale; CPR: Bystander cardiopulmonary resuscitation; DSM: Diagnostic and Statistical Manual of Mental Disorders; IES: The Impact of Event Scale; IES-R: The Impact of Event Scale Revised; OHCA: Out-of-hospital cardiac arrest; PCL: Post-traumatic stress disorder checklist; PRISMA: Preferred Reporting Items for Systematic Reviews and Meta-Analyses; PTSD: Post-traumatic stress disorder; SIGN: The Scottish Intercollegiate Guidelines Network}

Acknowledgements

Not applicable.

\section{Authors' contributions}

AR was a major contributor in writing the manuscript. RR and AR conducted the literature search and undertook the full-text review. EN evaluated and identified the assessment tools used in our review, and discussed the included papers with AR. CH, FF and LA contributed to the design and 
drafting of the work including revising of the study. All authors have agreed to be accountable for all aspects of the work in ensuring that questions related to the accuracy or integrity of any part of the work are appropriately investigated and resolved. All authors have read and approved the manuscript.

\section{Funding}

This research received no specific grant from any funding agency in the public, commercial or non-for-profit sectors.

\section{Availability of data and materials}

Data sharing is not applicable to this article as no datasets were generated or analysed during the current study.

\section{Ethics approval and consent to participate}

Not applicable.

\section{Consent for publication}

Not applicable.

\section{Competing interests}

The authors declare that they have no competing interests.

\section{Author details}

${ }^{1}$ Emergency Medical Services Copenhagen, University of Copenhagen, Telegrafvej 5, DK-2750 Ballerup, Copenhagen, Denmark. ²Department of Cardiology, Gentofte University Hospital, Gentofte Hospitalsvej 1, 2900, Hellerup, Copenhagen, Denmark.

\section{Received: 3 September 2019 Accepted: 14 October 2019}

Published online: 04 November 2019

\section{References}

1. Perkins GD, Olasveengen TM, Maconochie I, Soar J, Wyllie J, Greif R, et al. European resuscitation council guidelines for resuscitation: 2017 update. Resuscitation. 2018;123:43-50.

2. Neumar RW, Shuster M, Callaway CW, Gent LM, Atkins DL, Bhanji F, et al. 2015 American Heart Association guidelines update for cardiopulmonary resuscitation and emergency cardiovascular care.

3. Mozaffarian D, Benjamin EJ, Go AS, Arnett DK, Blaha MJ, Cushman M, et al. Heart disease and stroke statistics - 2015 update: a report from the American Heart Association. Circulation. 2015;131:e29-322.

4. Atwood C, Eisenberg MS, Herlitz J, Rea TD. Incidence of EMS-treated out-ofhospital cardiac arrest in Europe. Resuscitation. 2005:67:75-80.

5. Wissenberg M, Lippert FK, Folke F, Weeke P, Hansen CM, Christensen EF, et al. Association of National Initiatives to improve cardiac arrest management with rates of bystander intervention and patient survival after out-of-hospital cardiac arrest. JAMA. 2013;310:1377.

6. Hansen CM, Wissenberg M, Weeke P, Ruwald MH, Lamberts M, Lippert FK, et al. Automated external defibrillators inaccessible to more than half of nearby cardiac arrests in public locations during evening, nighttime, and weekends. Circulation. 2013;128:2224-31.

7. Hansen SM, Hansen CM. Folke F, Rajan S, Kristian Kragholm, Ejlskov L, et al. bystander defibrillation for out-of-hospital cardiac arrest in public vs residential locations. JAMA Cardiol. 2017;2:507-14.

8. Chan PS, McNally B, Tang F, Kellermann A. Recent trends in survival from out-of-hospital cardiac arrest in the United States. Circulation. 2014;130: 1876-82.

9. Berglund $E_{1}$ Claesson A, Nordberg P, Djärv T, Lundgren P, Folke F, et al. A smartphone application for dispatch of lay responders to out-of-hospital cardiac arrests. Resuscitation. 2018;126:160-5.

10. Ringh M, Rosenqvist M, Hollenberg J, Jonsson M, Fredman D, Nordberg P, et al. Mobile-phone dispatch of laypersons for CPR in out-of-hospital cardiac arrest. N Engl J Med. 2015;372:2316-25.

11. Smith CM, Wilson MH, Ghorbangholi A, Hartley-Sharpe C, Gwinnutt C, Dicker $B$, et al. The use of trained volunteers in the response to out-ofhospital cardiac arrest - the GoodSAM experience. Resuscitation. 2017; 121:123-6.

12. Mausz J, Snobelen P, Tavares W. "Please. Don't. Die.": A Grounded Theory Study of Bystander Cardiopulmonary Resuscitation. Circ Cardiovasc Qual Outcomes. 2018;11:e004035.
13. Mathiesen WT, Bjørshol CA, Braut GS, Søreide E. Reactions and coping strategies in lay rescuers who have provided CPR to out-of-hospital cardiac arrest victims: a qualitative study. BMJ Open. 2016;6:e010671.

14. Genest M, Levine J, Ramsden V. The impact of providing help: emergency workers and cardiopulmonary resuscitation attempts. J Trauma Stress. 1990; 3:305-13.

15. Abella BS, Aufderheide TP, Eigel B, Hickey RW, Longstreth WT, Nadkarni V, et al. Reducing barriers for implementation of bystander-initiated cardiopulmonary resuscitation: a scientific statement from the American Heart Association for healthcare providers, policymakers, and community leaders regarding the effectiveness of cardiopulmonary resuscitation. Circulation. 2008;117:704-9.

16. Moher D, Liberati A, Tetzlaff J, Altman DG. Preferred reporting items for systematic reviews and meta-analyses: the PRISMA statement. J Clin Epidemiol. 2009;62:1006-12.

17. O'Connor D, Green S, Higgins JPT. Chapter 5: defining the review questions and developing criteria for including studies. The Cochrane collaboration. Cochrane Handbook for Systematic Reviews of Interventions: In; 2011. http://Handbook.Cochrane.Org/

18. Harbour R, Miller J. A new system for grading recommendations in evidence based guidelines. BMJ. 2001;323:334-6.

19. Sveen J, Low A, Dyster-Aas J, Ekselius L, Willebrand M, Gerdin B. Validation of a Swedish version of the impact of event scale-revised (IES-R) in patients with burns. J Anxiety Disord. 2010;24:618-22.

20. Beck JG, Grant DM, Read JP, Clapp JD, Coffey SF, Miller LM, et al. The impact of event scale-revised: psychometric properties in a sample of motor vehicle accident survivors. J Anxiety Disord. 2008;22:187-98.

21. Schütte $N$, Bär $O$, Weiss $U$, Heuft G. Prediction of PTSD in police officers after six months - a prospective study. Span J Psychol. 2012;15:1339-48.

22. Hyland P, Brewin CR, Maercker A. Predictive validity of ICD-11 PTSD as measured by the impact of event scale-revised: a 15-year prospective study of political prisoners: ICD-11 PTSD and the impact of event scale-revised. J Trauma Stress. 2017;30:125-32.

23. Van Der Ploeg E, Mooren TTM, Kleber RJ, van der Velden PG, Brom D. Construct validation of the Dutch version of the impact of event scale. Psychol Assess. 2004:16:16-26.

24. Orsillo S. Measures for acute stress disorder and posttraumatic stress disorder. In: Practitioner's guide to empirically based measures of anxiety. New York; 2001. p. 255-307.

25. Horowitz M, Wilner M, Alvarez W. Impact of event scale: a measure of subjective stress. Psychomatic Med. 1979;41:209-18.

26. Motlagh H. Impact of Event Scale-Revised. J Physiother. 2010;56:203.

27. Asukai N, Yamamoto K. Reliability and Validity of the Japanese-Language Version of the Impact of Event Scale-Revised (IES-R-J): Four Studies of Different Traumatic Events. J Nerv Ment Dis. 2002:190(3):175-82.

28. Rash CJ, Coffey SF, Baschnagel JS, Drobes DJ, Saladin ME. Psychometric properties of the IES-R in traumatized substance dependent individuals with and without PTSD. Addict Behav. 2008;33:1039-47.

29. Zijlstra JA, Beesems SG, De Haan RJ, Koster RW. Psychological impact on dispatched local lay rescuers performing bystander cardiopulmonary resuscitation. Resuscitation. 2015;92:115-21.

30. Zilberg J, Weiss D, Horowitz M. Impact of event scale: a cross-validation study and some empirical evidence supporting a conceptual model of stress response syndromes. J Consult Clin Psychol. 1982;50:407-14.

31. Eid J, Larsson G, Johnsen BH, Laberg JC, Bartone PT, Carlstedt B. Psychometric properties of the Norwegian impact of event scale-revised in a non-clinical sample. Nord J Psychiatry. 2009;63:426-32.

32. Blake DD, Weathers F, Charney DS. The development of a clinician administered PTSD scale. J Trauma Stress. 1995:8:75-90.

33. Bryant RA, Creamer M, O'Donnell M, Silove D, McFarlane AC. The capacity of acute stress disorder to predict posttraumatic psychiatric disorders. J Psychiatr Res. 2012;46:168-73.

34. Blanchard E. Psychometric properties of the PTSD checklist (PCL). Behav Res Ther. 1996:34:669-73.

35. Blevins CA, Weathers FW, Davis MT, Witte TK, Domino JL. The posttraumatic stress disorder checklist for DSM-5 (PCL-5): development and initial psychometric evaluation: posttraumatic stress disorder checklist for DSM-5. Trauma Stress. 2015:28:489-98.

36. Waller M, Charlson FJ, Ireland REE, Whiteford HA, Dobson AJ. Time-course of PTSD symptoms in the Australian Defence force: a retrospective cohort study. Epidemiol Psychiatr Sci. 2016;25:393-402. 
37. Haraldsdóttir H, Gudmundsdóttir D, Elklit A. Volunteers and professional rescue workers: traumatization and adaptation after an avalanche disaster. J Emerg Manag. 2014;12(6):457-66.

38. Møller TP, Hansen CM, Fjordholt M, Pedersen BD, Østergaard D, Lippert FK. Debriefing bystanders of out-of-hospital cardiac arrest is valuable. Resuscitation. 2014:85:1504-11.

39. Weathers FW, Keane TM, Davidson JRT. Clinician-administered PTSD scale: a review of the first ten years of research. Depress Anxiety. 2001;13:132-56.

40. McEwen BS, Stellar E. Stress and the individual mechanisms leading to disease. Arch Intern Med. 1993;153:2093-101.

41. Gradus J. Prevalence and prognosis of stress disorders: a review of the epidemiologic literature. Clin Epidemiol. 2017;9:251-60.

\section{Publisher's Note}

Springer Nature remains neutral with regard to jurisdictional claims in published maps and institutional affiliations.

Ready to submit your research? Choose BMC and benefit from:

- fast, convenient online submission

- thorough peer review by experienced researchers in your field

- rapid publication on acceptance

- support for research data, including large and complex data types

- gold Open Access which fosters wider collaboration and increased citations

- maximum visibility for your research: over $100 \mathrm{M}$ website views per year

At BMC, research is always in progress.

Learn more biomedcentral.com/submissions 